\title{
A DEFENSORIA PÚBLICA NO NOVO CÓDIGO DE PROCESSO CIVIL: CONSOLIDAÇÃO DA INSTITUIÇÃO COMO INSTRUMENTO DE SUPERAÇÃO DOS OBSTÁCULOS AO ACESSO À JUSTIÇA
}

THE PUBLIC DEFENSE ON THE NEW BRAZILIAN CIVIL PROCEDURE CODE: INSTITUTION'S CONSOLIDATION AS AN INSTRUMENT TO OVERCOME OBSTACLES TO ACCESS TO JUSTICE

Felipe Caldas Menezes

Especialista em Direito Civil e Processual Civil pela Universidade Estácio de Sá

Defensor Público Federal

felipe.menezes@dpu.def.br

\section{RESUMO}

Aborda-se no presente trabalho as normas do Novo Código de Processo Civil que versam sobre a Defensoria Pública e sua atuação como instituição essencial à função jurisdicional do Estado, responsável pelo acesso à justiça das pessoas necessitadas. Analisa-se se o NCPC trouxe inovaçôes e avanços no ordenamento jurídico brasileiro sobre o tema. Constatou-se, da análise da legislação, da doutrina e da jurisprudência pátrias que, apesar de não haver integral ineditismo das inovaçóes normativas, a nova legislação processual representou um avanço sobre a temática da Defensoria Pública e do acesso à Justiça no Brasil, especialmente na confirmação de seu real papel.

Palavras-chave: Código. Processo Civil. Defensoria Pública. Acesso à Justiça.

\begin{abstract}
This study analyze the rules of The New Brazilian Civil Procedure Code about the Public Defense and its place as an Institution essential to the jurisdiction function of the State, responsible for the access to justice for the disadvantage people. This study addresses if the New Brazilian Civil Procedure brought innovations and advances on the Brazilian law system about the theme. It have been found, through the analysis of the legislation,
\end{abstract}


the doctrine and the jurisprudence that, in spite of there is no integral uniqueness in the law innovation, the new procedure law has represented a progress in the theme of Public Defense and about access to justice in Brazil, especially by the confirmation of its real role.

Keywords: Code. Civil Procedure. Public Defense. Access to justice.

Data de submissão: 10/12/2018

Data de aceitação: 03/01/2020

\section{SUMÁRIO}

INTRODUÇÃO 1. O DIREITO CONSTITUCIONAL PROCESSUAL E A DEFENSORIA PÚBLICA NO NCPC 2. CONCEITO DE DEFENSORIA PÚBLICA E ESPECTRO DE ATUAÇÃO INSTITUCIONAL 3. PRINCIPAIS NORMAS RELATIVAS À ATUAÇÃO DA DEFENSORIA PÚBLICA NO NCPC 3.1. Legitimidade para atuação em Ações e Incidentes com Repercussão Coletiva 3.2. Atuação da Defensoria Pública mediante a utilização dos Métodos de Solução Consensual de Conflitos 3.3. A intimação nos processos em que atua a Defensoria Pública e Prazo em Dobro 3.4. A Responsabilidade do Defensor Público 4. A DEFENSORIA COMO INSTITUICCÃO ESSENCIAL À FUNÇÃO JURISDICIONAL MOLDADA PARA SUPERAÇẢO DOS OBSTÁCULOS DO ACESSO À JUSTIÇA. CONSIDERAÇÓES FINAIS.

\section{INTRODUÇÁO}

O presente trabalho tem por objetivo analisar as repercussões do Novo Código de Processo Civil de 2015 (NCPC) na atuação da Defensoria Pública como Instituição vocacionada a garantir o acesso à Justiça das pessoas necessitadas.

A doutrina vem debatendo, em diversas searas, sobre os efeitos da nova legislação processual em relação às instituiçôes e institutos existentes no ordenamento jurídico brasileiro e no que pertine a um dos principais objetivos da nova legislação processual codificada, qual seja, o de dar maior efetividade às garantias constitucionais da razoável duração do processo e do acesso à Justiça.

O objetivo do trabalho é contribuir mediante a análise dos principais dispositivos trazidos pelo NCPC relativos à atuação institucional (sem a pretensão de análise de sua totalidade, por fugir ao escopo delimitado), da doutrina e da jurisprudência correlatas, analisando se representaram efetiva inovação sobre o tema no ordenamento jurídico pátrio, bem como se estão de acordo com os objetivos da nova codificação. 
A escolha do tema para análise em trabalho de conclusão de curso deu-se pela constante avaliação crítica das alterações processuais realizadas pelo NCPC, durante o curso de pósgraduação e pelo fato de o autor considerar que o estudo do tema pode levar a uma melhor compreensão das atribuiçôes da Instituição, e, das ferramentas processuais que estáo atualmente à sua disposiçáo, dentro do cenário da nova legislaçâo processual vigente, seja pelos próprios membros e servidores, seja pelos demais profissionais do Direito que lidam com a Instituição em seu dia a dia.

\section{O DIREITO PROCESSUAL CONSTITUCIONAL E A DEFENSORIA PÚBLICA NO NCPC}

Algumas das normas presentes no NCPC mais elogiadas pela doutrina processualista ${ }^{1}$ foram as contidas no Livro I, Título Único, Capítulo I, que traz as "Normas Fundamentais do Processo Civil" (arts. $1^{\circ}$ a 12 do NCPC), na medida em que trouxeram para o texto da codificação a visão expressa de que o "processo civil será ordenado, disciplinado e interpretado conforme os valores e as normas fundamentais estabelecidos na Constituição da República Federativa do Brasil”. ${ }^{2}$

Além dessa regra geral, que corresponderia à adoção de uma ótica de direito processual constitucional, ${ }^{3}$ outros dispositivos densificaram infraconstitucionalmente a aplicação de princípios constitucionais ${ }^{4}$ como o acesso à Justiça (art. $3^{\circ}$, caput, do NCPC c/c art. $5^{\circ}$, inciso XXXV, da CRFB), a razoável duraçáo do processo (art. $4^{\circ}$ do NCPC c/c art. $5^{\circ}$, inciso LXXVIII, da CRFB), do contraditório e da ampla defesa (art. $7^{\circ}$ do NCPC c/c art. 5०, inciso LV, da CRFB), da dignidade humana, da razoabilidade, da legalidade e da eficiência (art. $8^{\circ}$ do NCPC c/c arts. $1^{\circ}$, inciso III, 50, inciso LIV, e 37, caput, da CRFB), publicidade dos julgamentos e fundamentaçâo das decisóes judiciais (art. 11 do NCPC c/c art. 93, inciso IX, da CRFB).

\footnotetext{
1 Embora alguns processualistas façam a ressalva de que a observância das normas constitucionais, por ocuparem o ápice do ordenamento jurídico e servirem de fundamento de validade para as demais normas (visão kelseniana de hierarquia das normas), não necessitariam obrigatoriamente de serem mencionadas no Novo Código de Processo Civil (BUENO, C. S., coord., Comentários ao Código de Processo Civil Volume - 1. São Paulo: SaraivaJur, 2017, p. 22 e JUNIOR, N. N.; NERY, R. M. de A, Código de Processo Civil Comentado. 16a ed. São Paulo: Revista dos Tribunais, 2016, pp. 195-196, notas n. 2-4), acabam por aplaudir a finalidade didática dos dispositivos no sentido de estabelecer-se uma nova cultura de compreensão do sistema processual a partir da Constituição Federal, permitindo uma melhor concretização dos direitos (BUENO, C. S., Op. cit., p. 22; MARINONI, L. G.; ARENHART, S. C.; MITIDIERO, D. O Novo Processo Civil. São Paulo: Revista dos Tribunais, 2015, pp. 167-168; CAMBI, E.; OLIVEIRA, P. S. de. Autonomia e Independência Funcional da Defensoria Pública. In: Coleçáo Repercussóes do Novo CPC. Defensoria Pública, Volume 5, SOUSA, José Augusto Garcia de - coord., JR. Fredie Didier - coord. geral, Salvador: JusPodivm, 2016, pp. 52-65).

2 Art. $1^{\circ}$ do NCPC.

3 JUNIOR, N. N.; NERY, R. M. de A., Op. cit., p. 196, nota n. 5.

4 MARINONI, L. G.; ARENHART, S. C.; MITIDIERO, D. Op. cit., p. 168
} 
Neste verdadeiro "esforço constitucionalizante" do processo, ${ }^{5}$ a Defensoria Pública, instituição eleita pela CRFB como modelo estatal oficial ${ }^{6,7}$ de prestação da assistência jurídica integral e gratuita aos necessitados (art. 5º, inciso LXXIV, c/c art. $134 \mathrm{da}$ CRFB), o qual pode ser classificado como staff model, ${ }^{8}$ é inserida expressamente no texto do NCPC em título próprio (Livro III, Título VII) e com cerca de sessenta dispositivos referindo-se à atuação da Instituição. ${ }^{9}$

Logo, dispositivos relativos à Defensoria Pública, assim como os princípios e garantias processuais existentes na CRFB, foram inseridos expressamente no NCPC como uma forma de reafirmar a necessidade de enxergar-se o processo sob a ótica das normas constitucionais.

Nesse espírito, passa-se à análise dos principais dispositivos do NCPC, que tratam da Defensoria Pública e da atuação de seus membros, de forma a poder-se verificar a ocorrência de efetivo avanço sobre o tema na Lei no $13.105 / 2015$.

\section{CONCEITO DE DEFENSORIA PÚBLICA E ESPECTRO DE ATUAÇÁO INSTITUCIONAL}

O primeiro dispositivo do título próprio que trata da Defensoria Pública no NCPC é o art. 185, o qual apresenta a seguinte redação: "A Defensoria Pública exercerá a orientação jurídica, a promoção dos direitos humanos e a defesa dos direitos individuais e coletivos dos necessitados, em todos os graus, de forma integral e gratuita”.

A redação estabelece a função exercida por esta Instituição permanente e essencial à função jurisdicional do Estado, que já consta nos conceitos atualmente existentes nas redaçôes do art. 134, caput, da CRFB e do art. $1^{\circ}$ da Lei Complementar no 80/1994 (Lei Orgânica Nacional da Defensoria Pública - LONDP/1994).

$\mathrm{Na}$ esteira do já explanado no capítulo anterior, não houve grandes alteraçóes do papel exercido pela Defensoria Pública por meio da redação do art. 185 do NCPC, mas sim

5 RÉ, A. I. M. R. O Processo Civil em Xeque: Os Desafios e As Perspectivas de Um Novo Diploma. A Defensoria Pública e seu Papel. In: Coleçáo Repercussóes do Novo CPC. Defensoria Pública, Volume 5, SOUSA, J. A. G. de (coord.), JR. F. D. (coord. geral), Salvador: JusPodivm, 2016, pp. 52-65.

6 SILVA, H. M. da, Princípios Institucionais da Defensoria Pública. Brasília: Fortium, 2007, pp. 12-16. Art. 4º, $\$ 5^{\circ}$, da Lei Complementar no 80/1994, com redaçáo da Lei Complementar no 132/2009.

8 ALVES, C. F. Justiça para Todos! Assistência Jurídica nos Estados Unidos, na França e no Brasil. Rio de Janeiro: Lumen Juris, 2006, p. 45-50

9 SOUSA, J. A. G. de. A Defensoria Pública e o Código de Processo Civil de 2015: Novos Caminhos - e Responsabilidades - para uma Instituição enfim essencial. In: Coleçáo Repercussóes do Novo CPC. Defensoria Pública, Volume 5, SOUSA, J. A. G. de (coord.), JR. Fredie Didier (coord. geral), Salvador: JusPodivm, 2016, p. 470. ARAÚJO, J. A. O Litígio Coletivo da Posse dos Artigos 554 e 565 do Novo CPC e a Natureza da Atuaçáo da Defensoria Pública. In: Coleçáo Repercussóes do Novo CPC. Defensoria Pública, Volume 5, SOUSA, J. A. G. de (coord.), JR. Fredie Didier (coord. geral), Salvador: JusPodivm, 2016, p. 427. 
a consolidação do papel da Instituição no bojo da codificação. Cabe destacar que, mais uma vez, fica claro que o papel da Defensoria Pública no ordenamento jurídico vai além da sua função mais tradicional de atuação judicial e extrajudicial ${ }^{10} \mathrm{em}$ prol de pessoas naturais economicamente necessitadas (com hipossuficiência de recursos financeiros), especialmente no que se refere ao seu papel na tutela coletiva e na defesa de direitos humanos.

Ante à clara ampliação no ordenamento jurídico pátrio das funções institucionais da Defensoria Pública, não relacionadas especificamente com a necessidade econômica ou com a hipossuficiência de recursos financeiros, ${ }^{11}$ José Augusto Garcia de Sousa ${ }^{12}$ considera ultrapassada a classificação entre funçoos institucionais típicas e atípicas, sugerindo uma nova classificação.

O referido autor denominou, de um lado, de atribuiçóes "tradicionais" ou "tendencialmente individualistas" as que compreenderiam apenas as atribuiçóes ligadas exclusivamente à carência econômica e, de outro, denominou de atribuiçôes "não tradicionais" ou "tendencialmente solidaristas", aquelas que abrangem a proteção a um só tempo de pessoas carentes economicamente e de pessoas náo carentes financeiramente, ${ }^{13}$ as que beneficiariam pessoas não necessariamente carentes, mas com repercussão em favor de pessoa carente, ${ }^{14}$ bem como as que sejam direcionadas a sujeitos especialmente protegidos pela ordem jurídica, possuidores de outras carências que não a econômica, ${ }^{15}$ além daquelas em que a atuação se dá preponderantemente em favor de valores relevantes do ordenamento jurídico. ${ }^{16}$

Resta evidente, pois, tanto do texto normativo quanto da doutrina, a atuação da De-

10 Lembre-se que a assistência jurídica prevista nos arts. 50, inciso LXXIV, da CRFB/1988 é serviço público mais amplo do que a assistência judiciária referida em textos constitucionais anteriores e na Lei $\mathrm{n}^{\circ}$ 1.060/1950, na medida em que, ao contrário daquela, não fica adstrita ao âmbito judicial, abrangendo a orientação jurídica e a representação também em âmbito extrajudicial (ALVES, C. F.; PIMENTA, M. G. Acesso à Justiça: em preto e branco: Retratos Institucionais da Defensoria Pública. Rio de Janeiro: Lumen Juris, 2004, p. 103).

11 Para Felipe Kirchner "Os conceitos de 'necessidade' e 'insuficiência de recursos' (arts. 5o, LXXIV, e 134 da CRFB/88), bem como a designação legal de 'hipossuficiência' (artigo 4º, VII, da LC 80/94), não promovem uma restrição conceitual à dimensão econômica do indivíduo, o que advém, única e exclusivamente, de uma leitura incorretamente centrada no paradigma da Lei $n^{\circ} 1.060 / 50$, a qual adota o paradigma econômico por estar historicamente condicionada ao sistema de justiça gratuita, garantidora apenas do direito à gratuidade das custas e despesas processuais (KIRCHNER, F. Os métodos Autocompositivos na Nova Sistematização Processual Civil e o Papel da Defensoria Pública. In: Coleçáo Repercussóes do Novo CPC. Defensoria Pública, Volume 5, SOUSA, J. A. G. de (coord.), JR. Fredie Didier (coord. geral), Salvador: JusPodivm, 2016, p. 240).

12 SOUSA, J. A. G. de.Op. cit., pp. 483-485.

13 Aqui José Augusto Garcia de Sousa cita como exemplo uma ação civil pública relativa a direitos difusos (SOUSA, J. A. G. de. Op. it., p. 484).

14 Exemplifica o autor esta hipótese com a representação judicial de um casal abastado que visa à adoção de uma criança internada (SOUSA, J. A. G. de. Op. cit., p. 484).

15 Ilustra o autor citado esta hipótese com a defesa de um portador de deficiência (SOUSA, J. A. G. de. Op. cit., p. 484).

16 A defesa do réu sem advogado na área criminal (art. 263, parágrafo único, do Código de Processo Penal) e a curadoria especial na área cível (art. 72, caput e parágrafo único, do NCPC) são os exemplos citados pelo autor (SOUSA, J. A. G. de. Op. cit., p. 484). 
fensoria Pública em funções institucionais diversas daquelas tradicionalmente ligadas à necessidade de cunho econômico e à hipossuficiência de recursos financeiros, devendo ter especial destaque, nas atribuições não tradicionais, a atuação em prol da defesa de pessoas ou grupos de pessoas vulneráveis ${ }^{17}$ e na tutela de direitos humanos. ${ }^{18}$

Em relação à vulnerabilidade, a doutrina especializada ${ }^{19}$ defende que o conteúdo de tal expressão é melhor delimitado pelas denominadas "100 Regras de Brasília sobre Acesso à Justiça das Pessoas em Condição de Vulnerabilidade", formuladas na XIV Edição da Conferência Judicial Ibero-Americana, ${ }^{20}$ que em sua Secçáo $2^{\mathrm{a}}$ estabelece o conceito que se segue:

\section{Secção 2a.- Beneficiários das Regras}

1.- Conceito das pessoas em situação de vulnerabilidade

(3) Consideram-se em condição de vulnerabilidade aquelas pessoas que, por razáo da sua idade, género, estado físico ou mental, ou por circunstâncias sociais, económicas, étnicas e/ou culturais, encontram especiais dificuldades em exercitar com plenitude perante o sistema de justiça os direitos reconhecidos pelo ordenamento jurídico.

(4) Poderão constituir causas de vulnerabilidade, entre outras, as seguintes: a idade, a incapacidade, a pertença a comunidades indígenas ou a minorias, a vitimização, a migração e o deslocamento interno, a pobreza, o género e a privação de liberdade. A concreta determinação das pessoas em condição de vulnerabilidade em cada país dependerá das suas características específicas, ou inclusive do seu nível de desenvolvimento social e económico.

Isto mostra que a caracterização de situação de vulnerabilidade é bem mais ampla do que um conteúdo estritamente econômico (o qual, sem dúvidas, por si só também é importante fonte de vulnerabilidade de forma isolada ou exacerbando outras espécies de hipossuficiência ${ }^{21}$ ), e abrange dificuldades do exercício pleno do acesso à Justiça e dos demais direitos reconhecidos pelo ordenamento jurídico, decorrentes também de condiçóes

17 Atribuição melhor especificada no inciso IX do art. 4º da Lei Complementar no 80/1994.

18 Vide art. $3^{\circ}-\mathrm{A}$, inciso III, e art. $4^{\circ}$, incisos III e VI, da Lei Complementar no 80/1994.

19 KIRCHNer, F. Op. cit, p. 242. MAGNO, P. Defensoria Pública e Assistência Jurídica Internacional: Uma Leitura do Novo Código de Processo Civil à Luz do Direito Internacional dos Direitos Humanos. In: Coleçáo Repercussóes do Novo CPC. Defensoria Pública, Volume 5, SOUSA, J. A. G. de (coord.), JR. Fredie Didier (coord. geral), Salvador: JusPodivm, 2016, p. 622. SOUSA, J. A. G. de. Op. cit., pp. 483-484.

20 https://www.anadep.org.br/wtksite/100-Regras-de-Brasilia-versao-reduzida.pdf. Acesso em 16/02/2018.

21 MAGNO, P. Op. cit., pp. 621-623. 
pessoais relacionadas à idade ${ }^{22}$ ao gênero ${ }^{23}$ ao estado físico ou mental do indivíduo, ${ }^{24} \mathrm{ou}$ por circunstâncias sociais, éticas ou culturais.

Entende-se mais consentâneo, pois, com as normas que regulamentam a atuação da Defensoria Pública, tanto constitucional, quanto infraconstitucionalmente, que se adote o conceito de vulnerabilidade como norteador da delimitaçáo do conteúdo da atuaçáo da Instituição, revelando o real significado dos termos "insuficiência de recursos" e "necessitados" existentes nos arts. $5^{\circ}$, inciso LXXIV, e 134, da CRFB. ${ }^{25}$

Para concluir, com o objetivo de tentar simplificar e deixar mais autoexplicativa a terminologia utilizada, sugere-se uma nova classificação para as funçóes da Defensoria Pública, de acordo com a predominância de determinada espécie de necessidade/vulnerabilidade, quando da análise da configuraçấo de hipótese de atuação institucional: a) as de natureza econômica: aquelas em que prepondera o critério de situação financeira das pessoas ou grupos de pessoas que podem, concreta ou potencialmente, beneficiar-se da atuaçáo da Instituição, sendo certo que, uma vez configurada esta espécie de necessidade, prescindese da aferição de outras vulnerabilidades, principalmente porque as dificuldades financeiras servem para exacerbar outras espécies de necessidade eventualmente existentes; e b) as de natureza jurídico-sociais: aqui inseridas, de modo preponderante, as dificuldades de acesso à Justiça ou ao exercício de direitos que guardem relação com a idade (crianças, adolescentes, jovens e idosos), com as questóes de gênero (mulheres vítimas de violência doméstica, ${ }^{26}$ pessoas que sofrem discriminação ou têm seus direitos violados em razão de sua orientaçáo sexual ou identidade de gênero etc.), com o estado físico ou mental do indivíduo (pessoas portadoras de necessidades especiais, ${ }^{27}$ pessoas que não têm discernimento suficiente para a prática autônoma de atos da vida civil ${ }^{28}$ etc.) ou com circunstâncias

22 Em relação à idade o ordenamento jurídico brasileiro reconhece tanto em nível Constitucional quanto em nível infraconstitucional (por meio inclusive de leis específicas) a vulnerabilidade e a necessidade de especial proteção à criança, ao adolescente, ao jovem e ao idoso (arts. 227 e 230 da CRFB/1988 e Leis no 8.069/1990, 10.741/2003 e Lei no 12.852/2013, respectivamente Estatuto da Criança e do Adolescente ECA, Estatuto do Idoso e Estatuto da Juventude).

$23 \mathrm{O}$ art. $5^{\circ}$, inciso I, da CRFB/1988 positiva a igualdade de gênero.

24 Os arts. 7º, XXXI; 23, II; 24, XIV; 37, VIII; 40, $\$ 4^{\circ}$, I; 201, $\$ 1^{\circ} ; 203$, IV e V; 208, III; 227, caput e $\$ 1^{\circ}$, II, e $\$ 2^{\circ}$; e 244, da CRFB/1988 estabelecem diversas normas protetivas às pessoas portadoras de deficiência física e psíquica, o que também foi regulamentado infraconstitucionalmente pelo Estatuto da Pessoa com Deficiência (Lei no 13.146/2015).

25 LIMA, F. R. V. de. Um Novo Código de Processo Civil para Uma Nova Defensoria Pública. In: Coleçáo Repercussóes do Novo CPC. Defensoria Pública, Volume 5, SOUSA, J. A. G. de (coord.), JR. Fredie Didier (coord. geral), Salvador: JusPodivm, 2016, pp. 359-364.

26 Art. 28 da Lei no 11.340/2006 (Lei Maria da Penha).

27 Arts. $79, \$ \$ 1^{\circ}$ e $3^{\circ}$, da Lei $n^{\circ} 13.146 / 2015$ (Estatuto da Pessoa com Deficiência) e art. $3^{\circ}$ da Lei $n^{\circ}$ 7.853/1989 (este último com redaçấo modificada pelo art. 98 da Lei no 13.146/2015).

28 Neste particular destaca-se a função de curador especial da Defensoria Pública para o incapaz no momento da citação (art. 245, $\$ \$ 4^{\circ}$ e $5^{\circ}$, do $\mathrm{NCPC}$ ), seja no caso de incapaz (aqui também se inclui o menor de 18 anos - vulnerabilidade etária) sem representante legal ou no caso de conflito de interesses do incapaz com os de seu representante legal (art. 72, inciso I, e 671, inciso II, do NCPC), seja para a interdição do incapaz (art. $752, \$ 2^{\circ}$, do NCPC). 
sociais, ${ }^{29}$ étnicas ${ }^{30}$ ou culturais, incluindo-se, nos termos do conceito de vulnerabilidade das 100 regras de Brasília acima citadas, a privaçáo de liberdade. ${ }^{31}$

\section{PRINCIPAIS NORMAS RELATIVAS À ATUAÇÁO DA DEFENSORIA PÚBLICA NO NCPC}

Contextualizado o tema com a análise da constitucionalização do Direito Processual, mediante a inserção no NCPC de diversas normas previstas na CRFB/1988, inclusive no que tange às normas atinentes à Defensoria Pública, bem como partindo-se da análise mais ampla dos limites de sua atuação Institucional, agora faz-se necessário analisar de forma mais específica os principais dispositivos que versam sobre as atribuiçôes institucionais no NCPC.

\subsection{Legitimidade para atuaçáo em Açóes e Incidentes com Repercussáo Coletiva}

Historicamente, a primeira lei federal que deu ensejo a uma interpretação no sentido da legitimidade da Defensoria Pública para a propositura de açóes coletivas foi o Código de Proteção e de Defesa do Consumidor - CDC (Lei no 8.078/1990), especialmente por força da combinação do art. 82, inciso III, do CDC com o art. 4º, inciso XI, da LON$\mathrm{DP} / 1994,{ }^{32}$ sem prejuízo da previsão com o art. 21 da Lei no 7.347/1985 (Lei de Ação Civil Pública - LACP)..$^{33}$

Ao lado da legitimação ativa ad causam, sempre houve a possibilidade de representação

\footnotetext{
29 Não se pode perder de vista, ainda, a vulnerabilidade jurídica dos réus revéis citados por edital ou por hora certa em relação aos quais a Defensoria Pública também exercerá a curadoria especial (art. 72, inciso II e parágrafo único, c/c arts. $253, \$ 4^{\circ}$, e 257 , inciso IV, do NCPC), assim como a necessidade organizacional muito bem referida por Ada Pellegrini Grinover e que dá base para atuação da Instituição na tutela dos direitos coletivos, em gênero (GRINOVER, A. P. "Acesso à Justiça e o Código de Defesa do Consumidor". In: O Processo em evoluçáo, Rio de Janeiro: Forense Universitária, 1996, p. 117).

30 Aqui se insere a proteção das comunidades indígena (art. 231 da CRFB/1988) e às comunidades tradicionais, tl como a quilombola (art. 216, $\$ 5^{\circ}$, da CRFB/1988 e art. 68 do ADCT).

31 Este seria o caso da atuação na curadoria especial para o réu preso, enquanto náo constitui advogado (art. 72, inciso II, $1^{\text {a }}$ Parte do NCPC), da comunicação de prisão em flagrante para o réu sem advogado constituído (art. 306, $\$ 1^{\circ}$, do CPP, com a redação da Lei no 12.403/2011) e da atuaçáo da Defensoria como órgão de execução penal (arts. 16, 61, inciso VIII, 81-A, 81-B e 82, \$2º da Lei no 7.210/1984) e da Defensoria Pública da União no Sistema Penitenciário Federal (art. 5º, $\$ 1^{\circ}$, da Lei no 11.671/2008).

32 FILHO, L. P. da S. A. Comentários ao Código de Defesa do Consumidor. Direito Processual. São Paulo: Saraiva, 2002, p. 81.

33 Sobre a aplicação conjunta do CDC com a Lei de Ação Civil Pública para a aplicação geral dos dispositivos do CDC não apenas para processos relacionados à proteção do consumidor vide MENDES, A. G. de C. O Anteprojeto de Código Brasileiro de Processos Coletivos e a Legitimidade da Defensoria Pública para as Açốes Coletivas. In: A Defensoria Pública e os Processos Coletivos. Comemorando a Lei Federal 11.448, de 15 de janeiro de 2007, SOUSA, J. A. G. de (coord.), Rio de Janeiro: Lumen Juris, 2008, p. 52.
} 
de associaçóes economicamente necessitadas em juízo (art. $5^{\circ}$ da LACP c/c art. 82, inciso IV, do CDC). ${ }^{34}$

Ressalte-se, ainda, que os constantes questionamentos doutrinários e jurisprudenciais acerca da legitimidade especial da Defensoria Pública para tutela coletiva, tentando delimitar a sua pertinência temática às hipóteses em que os beneficiários fossem necessitados econômicos, levaram inclusive ao questionamento da constitucionalidade da Lei $\mathrm{n}^{\circ}$ $11.448 / 2007,{ }^{35}$ que incluiu expressamente a Defensoria Pública no rol dos legitimados ${ }^{36}$ para a propositura de ação civil pública.

$\mathrm{Na}$ evolução legislativa sobre o tema, tanto a Emenda Constitucional no $80 / 2014,{ }^{37}$ quanto a reforma da LONDP/1994, levada a efeito pela Lei Complementar no 132/2009, ${ }^{38}$ quanto os artigos 185 e 139, inciso X, do NCPC, vieram a reafirmar a vocação da Instituição para a tutela coletiva.

Como já comentado anteriormente, a adoção da interpretação mais elástica dos conceitos de hipossuficiência, necessidade e insuficiência de recursos, não os limitando a questốes de ordem econômico-financeira, já que o texto constitucional não o faz expressamente, resulta numa ampla legitimação da Defensoria Pública para a tutela coletiva, embora não ilimitada, bastando, nos termos do já decidido pelo Supremo Tribunal Federal (STF), tanto em controle concentrado de constitucionalidade, ${ }^{39}$ quanto em julgamento realizado com repercussão geral, ${ }^{40}$ que a tutela coletiva possa beneficiar, em tese, ${ }^{41}$ pessoas necessitadas. ${ }^{42}$

34 Lembre-se que acabou sendo pacificado o entendimento no sentido de que para as pessoas jurídicas, ao contrário das pessoas naturais para as quais a mera afirmação estabelece presunção relativa da situação de necessidade econômica, a gratuidade de justiça e a assistência judiciária somente devem ser deferidas se houver efetiva comprovaçáo da necessidade econômica (vide art. $4^{\circ}$ da Lei no $1.060 / 1950$, Súmula no 481 do STF e o atualmente disposto no art. $99, \S 3^{\circ}$, do NCPC).

35 Posicionamento que deu origem à propositura da $\mathrm{ADI} 3.943$ perante o STF.

36 Art. 5º, inciso II, da Lei no 7.347/85, com redaçấo dada pela Lei no $11.448 / 2007$.

37 Art. 134 da CRFB/1988 com redação da Emenda Constitucional no 80/2014.

38 Art. 50, inciso II, da Lei no 7.347/1985, com redação da Lei no 11.448/2007; arts. 1º, 4º, incisos VII, VIII, X, XI, XXII, e 15-A, da Lei Complementar no 80/1994 (redação da Lei Complementar no 132/2009); e arts. 139, inciso X, e 185, caput, do NCPC.

39 STF. ADI 3943, Relator(a): Min. CÁRMEN LÚCIA, Tribunal Pleno, julgado em 07/05/2015, ACÓRDÁO ELETRÔNICO DJe-154 DIVULG 05-08-2015 PUBLIC 06-08-2015.

40 STF. RE 733433, Relator(a): Min. DIAS TOFFOLI, Tribunal Pleno, julgado em 04/11/2015, ACÓRDÃO ELETRÔNICO REPERCUSSÃO GERAL - MÉRITO DJe-063 DIVULG 06-04-2016 PUBLIC 07-04-2016

${ }^{41}$ Melhor especificando esta análise do benefício, em tese, Fábio Shwartz defende que a melhor exegese "é do benefício potencial aos hipossuficientes e socialmente vulneráveis" (SCHWARTZ, Fabio. O Novo CPC e os Avanços Legislativos que Contribuem na Superação de Obstáculos e na Afirmação da Vocação Institucional da Defensoria Pública para Atuação na Tutela Coletiva. In: Coleçáo Repercussóes do Novo CPC. Defensoria Pública, Volume 5, SOUSA, J. A. G. de - coord., JR. Fredie Didier - coord. geral, Salvador: JusPodivm, 2016, p. 194-196).

42 Encontra-se, ainda, na jurisprudência, especialmente no que tange aos direitos individuais homogêneos, algumas vozes dissonantes que pretendem limitar a legitimidade da Defensoria Pública a hipóteses em que haja comprovação da situação de necessidade do grupo a ser beneficiado, citando-se, como exemplo o julgamento do REsp 1192577/RS (STJ. Rel. Ministro LUIS FELIPE SALOMÃO, QUARTA TURMA, julgado em 15/05/2014, DJe 15/08/2014). No entanto, tal espécie de restrição vem sendo superada, como 
Ainda no que tange à tutela coletiva por meio da atuação da Defensoria Pública, o Superior Tribunal de Justiça $(\mathrm{STJ})^{43}$ entende que a legitimaçấo da Instituição para o ajuizamento inicial (fase coletiva) independe da natureza do interesse coletivo lato sensu tutelado (interesses coletivos stricto sensu, difusos ou individuais homogêneos, com definição legal no art. 81, parágrafo único, incisos I a III, do CDC) ${ }^{44}$ bastando que haja benefício, em tese, de pessoas em situação de vulnerabilidade. Mas nas açóes relativas à tutela de interesses individuais homogêneos, após a fase coletiva que perdura até a prolação de sentença genérica de procedência, na fase individual de liquidação e execução da condenação para cada pessoa, apesar de a sentença genérica poder ser liquidada e executada por qualquer pessoa, ${ }^{45}$ a Instituição somente poderia assistir pessoas com comprovada insuficiência de recursos.

Além da tutela coletiva prevista no art. 185, caput, e no art. 139, inciso X, ambos do NCPC, que já autorizavam a Defensoria Pública a adotar as ditas atuações moleculares, ${ }^{46}$ confirmando a vocação da Instituiçẫo para exercer suas atribuiçôes em açôes e incidentes com repercussão coletiva, o NCPC traz, ainda, de forma expressa, a atuação da Defensoria Pública como legitimada para formular, de forma autônoma (art. 977, inciso III, e 947, \$ $1^{\circ}$, do NCPC) ou assistindo determinada parte necessitada (art. 977, inciso II, e 947, $\$ 1^{\circ}$, do NCPC), pedido de instauração de Incidente de Resolução de Demandas Repetitivas IRDR, quanto de Incidente de Assunção de Competência. ${ }^{47}$

Deve-se ressaltar, por fim, ainda, no que tange à atuação da Instituição em ações e incidentes de repercussão coletiva, a participação da Defensoria Pública em açôes possessórias com polo passivo composto por grande número de pessoas, quando o litígio envolver

se pode extrair do julgamento dos Embargos de Divergência neste mesmo processo, em que, posteriormente, diante do posicionamento do STF na ADI 3.943/STF, da relevância do direito tutelado (direito à saúde de consumidores idosos) e do fato de as vulnerabilidades tuteladas pela Defensoria Pública náo se restringirem à questão de cunho econômico, acabou por superar julgamento anterior do STJ e reconhecer a legitimidade da Defensoria Pública para a tutela coletiva de interesse caracterizado como individual homogêneo (STJ. EREsp 1192577/RS, Rel. Ministra LAURITA VAZ, CORTE ESPECIAL, julgado em 21/10/2015, DJe 13/11/2015). Em doutrina, defendendo a legitimidade da Defensoria Pública para tutela coletiva independentemente da natureza do direito tutelado vide: FILHO, E. S. G. Defensoria Pública e a Tutela Coletiva de Direitos. Teoria e Prática. Salvador: JusPodivm, 2016, pp. 100-103. PINHO, H. D. B. de. A Legitimidade da Defensoria Pública para propositura de Açóes Civis Públicas: Primeiras Impressōes e Questôes Controvertidas. In: A Defensoria Pública e os Processos Coletivos. Comemorando a Lei Federal 11.448, de 15 de janeiro de 2007, SOUSA, J. A. G. de (coord.), Rio de Janeiro: Lumen Juris, 2008, pp. 183-187.

43 STJ. REsp 1449416/SC, Rel. Ministro RICARDO VILLAS BÔAS CUEVA, TERCEIRA TURMA, julgado em 15/03/2016, DJe 29/03/2016.

44 ORDACGY, A. da S. As açóes Coletivas pela Defensoria Pública na novel reforma da Lei Complementar no 80/94. In: Uma Nova Defensoria Pública Pede Passagem. Reflexôes sobre a Lei Complementar 132/09. SOUSA, J. A. G. de (coord.). Rio de Janeiro: Lumen Juris, 2011, pp. 245-247.

45 SCHWARTZ, F. O Novo CPC e os Avanços Legislativos que Contribuem na Superação de Obstáculos e na Afirmação da Vocação Institucional da Defensoria Pública para Atuação na Tutela Coletiva. In: Coleção Repercussóes do Novo CPC. Defensoria Pública, Volume 5, SOUSA, J. A. G. de (coord.), JR. Fredie Didier (coord. geral), Salvador: JusPodivm, 2016, p. 199.

46 SOUSA, J. A. G. de. Op. cit., pp. 489-491 apud Kazuo Watanabe.

47 JEREISSATI, R. G. do A. O Incidente de Resolução de Demandas Repetitivas e o Incidente de Assunção de Competência como Mecanismos de Uniformização da Jurisprudência nos Tribunais e a Participação da Defensoria Pública na Formação dos Precedentes CPC/2015. Perspectiva da Defensoria Pública, Franklyn Roger Silva (coord.). Salvador: JusPodivm, 2017, pp. 518-522. 
pessoas em situação de hipossuficiência econômica objetivando tutelar o direito social à moradia e à função social da propriedade ${ }^{48}\left(\operatorname{art} .554, \S 1^{\circ}\right.$, e $565, \$ 2^{\circ}$, do NCPC) ${ }^{49}$ e a possibilidade de a Instituição intervir como amicus curiae em ações ou incidentes com repercussão coletiva, podendo, nesta última hipótese, valer-se tanto da previsão genérica do art. 138 do NCPC, quanto de disposiçốes específicas como as do IRDR (art. 983 do $\mathrm{NCPC}^{50}$ ), dos precedentes (art. 927, $\$ 2^{\circ}$, do NCPC), do incidente de inconstitucionalidade (art. $950, \$ \$ 2^{\circ}$ e $3^{\circ}$, do NCPC), na análise da repercussão geral (art. 1.035, $\$ 4^{\circ}$, do NCPC) e no julgamento de recursos especiais e extraordinários repetitivos (art. 1.038, inciso I, do NCPC). ${ }^{51}$

As disposiçóes do NCPC nesse ponto, apesar de não inovarem totalmente o ordenamento jurídico em relação à atuação da Defensoria Pública em ações e incidentes metaindividuais, reforçam tal papel, na medida em que, ao trazerem novos institutos relativos ao tema, em nenhum momento (ao contrário), excluem a possibilidade de participação dos mesmos pela Instituição.

\subsection{Atuaçáo da Defensoria Pública mediante a utilizaçáo dos Métodos de Soluçáo Consensual de Conflitos}

No que tange à utilização de mecanismos alternativos de resolução de conflitos, o art. $4^{\circ}$, inciso II, da LONDP/1994, com a redação que lhe foi conferida pela Lei Complementar no 132/2009, já deixava clara a prioridade a ser dada pelo Defensor Público na tentativa de solução extrajudicial dos conflitos de interesses, pela utilização da mediação, da conciliação e da arbitragem, dentre outras técnicas de composição e administração de conflitos.

Interpretando-se o dispositivo conjuntamente com o artigo 18, inciso III, da LON$\mathrm{DP} / 1994$, conclui-se que, antes de propor uma ação judicial, e quando possível, ${ }^{52}$ deve o membro da Defensoria Pública tentar resolver extrajudicialmente o litígio. Mas, mesmo quando já proposta a açáa judicial, o Defensor Público, assim como os demais atores do processo (arts. $3^{\circ}, \$ 3^{\circ}$, e 139 , inciso V, do NCPC), devem, em havendo possibilidade, tentar obter a resolução do conflito de interesses mediante a aplicação de técnicas alternativas.

\footnotetext{
48 FLEXA, A.; MACEDO, D.; BASTOS, F. Novo Código de Processo Civil. Temas Inéditos, Mudanças e Supressóes. 2a ed. Salvador: JusPodivm, 2016, p. 190.

49 Apesar de muito se debater sobre o alcance de tais dispositivos em relação à atuação da Defensoria Pública, parte da doutrina sustenta que, por se tratar de litígio possessório que quase sempre envolve pessoas hipossuficientes, a Instituiçáo deve atuar mesmo que todos os réus constituam advogado para representá-los (SOUSA, J. A. G. de. Op. cit., p. 495-498).

50 JEREISSATI, R. G. do A. Op. cit., pp. 522-529.

51 SOUSA, J. A. G. de. Op. cit., pp. 490-491.

52 Deve-se atentar para o fato de que, nem sempre, dada a natureza do direito material envolvido, que pode ser indisponível ou perecível, é possível, sem causar prejuízos à parte assistida pela Defensoria Pública, efetuar qualquer tentativa prévia de resoluçáo extrajudicial do conflito, o que deve ser sopesado pelo Defensor Público, dentro de sua independência funcional (art. 43, inciso I, da Lei Complementar no 80/1994).
} 
Outro dispositivo a ser destacado neste particular é o que renova a previsão do art. $4^{\circ}, \mathbb{p}$ $4^{\circ}$, da LONDP/1994, no sentido de que o instrumento de transaçáo referendado pela Defensoria Pública, nos termos do art. 784, inciso IV, do NCPC, constitui título executivo extrajudicial, embora a redação da LONDP/1994 seja mais técnica do que o NCPC no particular, mencionando que, além da transação, a conciliação e a mediação subscritas pelo Defensor Público constituirão título executivo extrajudicial, ainda que celebrada com pessoa jurídica de direito público.

Assim, dentro do espírito do NCPC de privilegiar a utilização de métodos consensuais de solução de conflitos, com destaque para a mediação e a conciliação, como uma tentativa de mudança da cultura adversarial de judicializaçáo impregnada não só nas partes, mas nos próprios operadores do Direito, ${ }^{53}$ a Defensoria Pública desponta como um dos principais atores dessa necessária transformação, não só participando ativamente da aplicação prática dos diversos mecanismos alternativos de soluçấo de conflitos, mas também valendo-se da sua função institucional de difusão e conscientização da cidadania e do ordenamento jurídico (art. 4\% , inciso III, da LONDP/1994). ${ }^{54}$

\subsection{A intimação nos processos em que atua a Defensoria Pública e prazo em dobro}

O NCPC reafirma em seu art. 186, caput e $₫ 1^{\circ}$, as prerrogativas de os membros da Defensoria Pública receberem intimaçóes pessoais e terem os seus prazos contados em dobro nos processos em que a Instituição atua, as quais já contavam com positivação no art. $4^{\circ}$, inciso V, e no inciso I, dos arts. 44, 89 e 128, todos da LONDP/1994.

A existência da intimação pessoal e da contagem em dobro dos prazos processuais para a Defensoria Pública, enquanto prerrogativas que se prestam a servir de instrumento necessário ao desempenho das atribuiçóes institucionais por seus membros, ${ }^{55}$ deve-se ao grande volume de processos judiciais e extrajudiciais acompanhados por cada Defensor Público, servindo, em última análise, para, ao contrário de gerar desigualdade, garantir a possibilidade de cumprimento dos prazos processuais pelos membros da Instituição, tratando desigualmente os desiguais, de forma a atender a isonomia em seu aspecto material e não meramente formal. ${ }^{56}$

Neste particular da intimação pessoal da Defensoria Pública e da contagem dos seus prazos em dobro, as únicas inovaçóes normativas do NCPC foram a previsão expressa de que a intimação pessoal mediante vista dos autos da Instituição pode dar-se, além do mecanismo tradicional de carga ou remessa física, por meio eletrônico ${ }^{57}$ (art. 186, $₫ 1^{\circ}$,

$53 \quad$ KIRCHNER, F. Op. cit., p. 206.

54 KIRCHNER, F. Op. cit., p. 250.

55 MORAES, G. P. de. Instituiçóes da Defensoria Pública. São Paulo: Malheiros Editores, 1999, pp. 276-277.

56 ESTEVES, D.; SILVA, F. R. A. Princípios Institucionais da Defensora Pública. $2^{\text {a }}$ ed. Rio de Janeiro: Forense, 2017, pp. 627-628.

57 ROCHA, F. B. Os Impactos do Novo CPC na Defensoria Pública: Intimaçáo Pessoal e Prazo em Dobro Coleção Repercussões do Novo CPC. Coletiva. In: Coleçáo Repercussóes do Novo CPC. Defensoria Pública, Volume 5, SOUSA, J. A. G. de (coord.), JR. F. D. (coord. geral), Salvador: JusPodivm, 2016, pp. 272-274. 
do NCPC), que remete ao art. $183, \$ 1^{\circ}$, do NCPC, ${ }^{58}$ à positivação da extensão da contagem dos prazos em dobro aos escritórios de prática jurídica de Faculdades de Direito e às entidades que prestam assistência jurídica na impossibilidade de atuação da Defensoria Pública, mediante convênio com esta Instituição (art. 186, $\$ 3^{\circ}$ do NCPC), além da exclusão da aplicação da contagem do prazo de forma dobrada, no caso de a lei estabelecer expressamente prazo específico para a Defensoria Pública (art. 186, $\$ 4^{\circ}$, do NCPC).

Com a referida realidade do grande volume de trabalho e com a dificuldade, em razão disso, de um contato mais próximo e frequente com cada um de seus assistidos, com acerto o legislador do NCPC trouxe as previsões de intimação pessoal da parte nos arts. $186, \$ 2^{\circ}$ (intimação quando o ato processual depender de providência ou informação que somente pela parte possa ser realizada ou prestada), $513, \$ 2^{\circ}$, inciso II (intimação inicial no cumprimento de sentença), $876, \$ 1^{\circ}$, inciso II, (intimação no procedimento de adjudicação de bens), todos do NCPC. Na mesma linha, o NCPC previu no art. 455, $\$ 4^{\circ}$, inciso IV, que a intimação pessoal de testemunhas arroladas pela Defensoria Pública será feita judicialmente.

Destaque-se, por fim, que a previsão legal do art. $513, \S 2^{\circ}$, inciso II, do NCPC foi responsável pela superaçáo de entendimento anteriormente adotado pelo STJ, no sentido de que a intimação da parte para o cumprimento de sentença poderia dar-se por intermédio da Defensoria Pública, não sendo necessária a intimação pessoal da parte assistida. ${ }^{59}$

\subsection{A responsabilidade do Defensor Público}

Inovou também o NCPC ao positivar expressamente dispositivos que dizem respeito à responsabilidade do Defensor Público, seja no aspecto civil, seja em relação a algumas condutas processuais.

O art. 187 do NCPC traz a previsão de que o Defensor Público pode ser regressivamente responsabilizado civilmente pelos danos que a sua atuação institucional vier a causar em caso de atuação institucional com dolo ou fraude, tal como ocorre com os Magistrados (art. 143, inciso I, do NCPC), com os Membros do Ministério Público (art. 181 do NCPC) e com os Advogados Públicos (art. 184 do NCPC). ${ }^{60}$

Regressivamente responsável, pois, quando exerce suas atribuiçóes Institucionais na prestação da assistência jurídica integral e gratuita age como agente público, nesta qualidade, respondendo primeiramente o Estado. Assim, caso o Estado venha a ser

58 Embora tal conclusão já pudesse ser extraída dos arts. $2^{\circ}$ e $5^{\circ}$, caput e $\$ 6^{\circ}$, da Lei no $11.419 / 2006$.

59 STJ. REsp 1280605/SP, Rel. Ministra NANCY ANDRIGHI, Rel. p/ Acórdão Ministro SIDNEI BENETI, TERCEIRA TURMA, julgado em 19/06/2012, DJe 11/12/2012; AgRg no AREsp 36.371/RJ, Rel. Ministro RAUL ARAÚJO, QUARTA TURMA, julgado em 26/06/2012, DJe 01/08/2012; AgRg nos EDcl no REsp 1535200/SP, Rel. Ministro MARCO AURÉLIO BELLIZZE, TERCEIRA TURMA, julgado em 03/12/2015, DJe 14/12/2015.

60 SILVA, F. R. A. A Formatação Processual da Defensoria Pública no Novo Código de Processo Civil. In: CPC/2015. Perspectiva da Defensoria Pública, Franklyn Roger Silva (coord.). Salvador: JusPodivm, 2017, p. 212. 
condenado a reparar civilmente outrem em razão da atuação de seu agente (Defensor Público), somente terá o direito de regresso contra este no caso de atuação com dolo ou fraude, ou seja, configurando-se exceção à regra geral de que o regresso em face do agente público ocorre quando há atuação com, no mínimo, culpa (art. 37, $\$ 6^{\circ}$, da CRFB e do art. 43 do Código Civil/2002). ${ }^{61}$

Mas o NCPC não se restringe a tratar da responsabilidade civil pessoal do Defensor Público de forma genérica, trazendo também disposiçóes relativas à responsabilidade pessoal do mesmo por algumas condutas específicas de cunho processual, tal como a de arcar com as despesas processuais relativas a atos adiados ou cuja repetição for necessária, se houver dado causa ao adiamento ou à repetiçáo (art. 93 do NCPC), bem como a de ser multado caso não restitua os autos do ato processual a ser praticado, em caso de remessa ou vista dos autos físicos (art. 234, $\$ 4^{\circ}$, do NCPC).

Em relação à aplicação dos referidos dispositivos (art. 93 e 234, $\$ 4^{\circ}$, do NCPC), parte da doutrina defende que eles devem ser interpretados conjuntamente com o art. 187 do NCPC, somente respondendo pessoalmente o Defensor Público, de forma regressiva, se vier a praticar o ilícito com dolo ou fraude. ${ }^{62}$

É certo, outrossim, que, no caso de descumprimento dos deveres processuais previstos no art. 77 do NCPC, a responsabilidade disciplinar do Defensor Público será apurada pela Corregedoria, defendendo a doutrina que o parâmetro para a responsabilização funcional do membro da Instituição é a prática de conduta com dolo ou fraude, nos limites do art. 187 do NCPC. ${ }^{63}$

Percebe-se de tais dispositivos que o Defensor Público é tratado em posição de igualdade no que tange aos demais agentes políticos que exercem funçóes essenciais à Justiça, o que é compatível com a importância do seu papel no sistema de justiça.

\section{A DEFENSORIA COMO INSTITUIÇÃO ESSENCIAL À FUNÇÃO JURISDIONAL MOLDADA PARA A SUPERAÇÁO DOS OBSTÁCULOS DO ACESSO À JUSTIÇA}

Após a análise das disposiçóes no NCPC acerca da Defensoria Pública, percebe-se o reconhecimento definitivo do seu status de função essencial à função jurisdicional do Estado no ordenamento jurídico brasileiro.

Com o reconhecimento da atribuição institucional de atuação da Defensoria Pública em favor de grupos vulneráveis, ou seja, em uma atuação de cunho mais solidarista e menos

\footnotetext{
${ }_{61}$ JUNIOR, N. N.; NERY, R. M. de A., Op. cit., p. 753, notas n. 2-3. SILVA, Franklyn Roger Alves. Op. cit., pp. 212-213.

62 REIS, G. A. S. dos. O Novo Código de Processo Civil e a Defensoria Pública do Século XXI: O Regime Jurídico de um Novo Ator Processual. In: Coleçáo Repercussóes do Novo CPC. Defensoria Pública, Volume 5, SOUSA, J. A. G. de (coord.), JR. F. D. (coord. geral), Salvador: JusPodivm, 2016, p. 419.

63 SILVA, F. R. A. Op. cit., p. 212.
} 
individualista, ${ }^{64}$ a Instituição acaba por abarcar as 3 (três) ondas renovatórias ${ }^{65}$ de acesso à Justiça delineadas no importante trabalho realizado no "Projeto de Florença", por Mauro Cappelletti e Bryant Garth. ${ }^{66}$

A primeira onda renovatória abrange a assistência judiciária para os pobres, a qual é garantida por meio da Defensoria Pública na prestação da assistência jurídica em prol dos economicamente vulneráveis (atribuiçâo mais tradicional da Instituição em casos de hipossuficiência financeira da parte).

A segunda onda renovatória diz respeito à representaçáo dos interesses coletivos, a qual, como já referido acima, foi assegurada à Defensoria Pública por meio tanto da previsão constitucional, quanto da legislação infraconstitucional, sendo importante destacar as importantes decisóes do STF e STJ sobre o tema colacionadas acima, reconhecendo a compatibilidade desta atribuição com o texto constitucional, caso a tutela de interesses coletivos, em gênero, possa beneficiar, em tese, pessoas necessitadas.

Não se pode deixar de destacar também a existência de um desdobramento da segunda onda de acesso à Justiça concernente aos procedimentos piloto e à uniformizaçáo da jurisprudência, ${ }^{67}$ em relação ao qual se insere a recente atribuição conferida à Defensoria Pública para deflagração de "processos-piloto", que se prestam a assegurar a construção de precedentes que serão vantajosos no julgamento de casos individuais, tais como o IRDR e a assunção de competência (art. 977, inciso III, e 947, $\$ 1^{\circ}$, do NCPC).

A terceira onda renovatória, denominada de "o enfoque do acesso à Justiça", traz uma concepção mais ampla, para além da garantia da representação de advogado e da tutela de interesses coletivos, preocupando-se com o aprimoramento do acesso à Justiça com a superaçáo de problemas relativos aos procedimentos judiciais, aos custos e ao tempo de duraçáo do processo.

No sistema brasileiro, a terceira onda abrangeria a ênfase crescente na resoluçáo alternativa de conflitos (juízo arbitral, conciliação, mediação etc.), contexto em que a Defensoria Pública atua na prevenção de conflitos com a utilização prioritária de métodos alternativos de soluçáo de litígios (art. $3^{\circ}, \S 3^{\circ}$, do NCPC c/c art. $4^{\circ}$, inciso II, da LONDP/1994), além de abranger a atuação perante os Juizados Especiais (art. 4º, inciso XIX, da LONDP/1994), que constituem órgãos jurisdicionais criados para um procedimento mais célere, simplificado e informal com o objetivo de superar entraves ao acesso à Justiça.

Mesmo para aqueles que defendem a existência de ao menos mais uma onda renovatória de acesso à Justiça, a qual estaria relacionada à internacionalização da proteção dos Di-

${ }^{64}$ SOUSA, J. A. G. de. Op. cit., pp. 483-485.

65 JÚNIOR, A. B. Princípios Institucionais da Defensoria Pública da Uniáo. Porto Alegre: Verbo Jurídico, 2014, pp. 61-65.

66 CAPPELLETTI, M.; BRAYNT, G. Acesso à Justiça. Trad. Ellen Gracie Northfleet. Porto Alegre: Sergio Antonio Fabris Editor, 1988, pp. 31-73.

67 ESTEVES, D.; SILVA, F. R. A. Op. cit., pp. 33-35. 
reitos Humanos, ${ }^{68}$ aqui também a Defensoria Pública está inserida como mecanismo de superação de dificuldades, em razáo tanto do disposto no art. 185 do NCPC (o qual reproduz disposições da CRFB e da LONDP/1994 no sentido da legitimação da Instituição para a defesa dos Direitos Humanos, de pessoas em situação de vulnerabilidade), quanto da possibilidade de formulação de representações aos sistemas internacionais de proteção de Direitos Humanos com postulação perante seus órgãos, conforme previsão expressa do art. $4^{\circ}$, inciso VI, da LONDP/1994.

Conclui-se, pois, que a Defensoria Pública constitui atualmente mecanismo ainda mais eficiente de acesso à Justiça, na medida em que o NCPC reforça a Instituição com normatizaçâo suficiente para superar os obstáculos que podem impedir ou dificultar o exercício da garantia constitucional prevista no art. 50, inciso XXXV, da CRFB.

\section{CONSIDERAÇÓES FINAIS}

Impóe-se, agora, que se proceda a uma síntese das principais ideias expostas no presente trabalho, da forma que segue abaixo:

1. As normas fundamentais do processo civil, tratadas nos arts. $1^{\circ}$ a 12 do NCPC e outras espalhadas pela nova codificação, positivaram uma visão de Direito Processual Constitucional, isto é, a noção de que o sistema processual somente pode ser entendido a partir dos valores contidos na CRFB.

2. Nessa esteira, a Defensoria Pública foi contemplada com regulamentação específica de sua atuação em título próprio e com outros dispositivos espalhados pela Lei $n^{\circ}$ $13.105 / 2015$ (cerca de 60).

3. A previsão do art. 185 do NCPC, apesar de trazer um conceito mais enxuto da atuação da Defensoria Pública, destaca os seus pontos principais, quais sejam, de promoção não só de assistência judicial individual, mas de orientação jurídica e de exercício de papel fundamental na promoção de direitos humanos e na legitimação para a tutela coletiva em prol de pessoas sujeitas à situação de vulnerabilidade (não apenas em prol de pessoas ou grupos economicamente necessitados).

4. Dentro dessa visão mais ampla das atribuiçôes da Defensoria Pública, desvinculando-a da premissa de que atuação estaria autorizada exclusivamente em hipótese de pessoa com insuficiência de recursos financeiros, a doutrina inclina-se pela superação da classificação das funçôes institucionais em típicas e atípicas. Destacou-se, neste ponto, a sugestão doutrinária de classificação de atribuiçôes em tradicionais (tendencialmente individualista) e não tradicionais (tendencialmente solidarista, sendo estas últimas, ao contrário das primeiras, não vinculadas estritamente a questóes econômicas).

68 ESTEVES, D.; SILVA, F. R. A. Op. cit., pp. 40-45. 
5. As denominadas "100 Regras de Brasília sobre Acesso à Justiça das Pessoas em Condição de Vulnerabilidade" melhor delimitaram, de forma mais consentânea com o ordenamento jurídico atual, o conceito de vulnerabilidade/necessidade (objeto de atuação da Defensoria Pública).

6. Diante desse quadro mais técnico-sistemático de análise do conteúdo das funções institucionais, este autor sugeriu uma nova classificaçấo, a qual visa a facilitar a análise da presença ou não de atribuição da Defensoria Pública, ou seja, se há ou não hipótese de necessidade/vulnerabilidade. Assim, distinguiu as necessidades/vulnerabilidades de natureza econômica, cujo critério preponderante é o de análise da situaçáo financeira dos destinatários do serviço de assistência jurídica integral e gratuita, das de natureza jurídico-social, em relação às quais predomina a verificação das dificuldades de acesso à Justiça com base em situaçóes diversas da financeira, destacando-se situaçóes em que o próprio ordenamento jurídico confere especial proteção com a finalidade de propiciar verdadeira isonomia material.

7. Dentro das principais normas objeto de análise relativas à atuação da Defensoria Pública existentes no NCPC, destacaram-se: a) as que tratam da legitimidade da Instituição para atuação em açôes e incidentes com repercussão coletiva; b) as que versam sobre a atuação da Defensoria Pública por meio da utilização de métodos de solução consensual de conflitos; c) as que regulamentam a forma como se efetivam as intimaçóes nos processos em que a Defensoria Pública atua e a contagem em dobro dos prazos processuais; e d) aquelas que tratam da responsabilidade dos Defensores Públicos.

8. A análise das principais disposiçôes relativas à atuação da Defensoria Pública existentes no NCPC, conjugada com o estudo das denominadas ondas renovatórias, levou à conclusão de que a Instituição atualmente constitui mecanismo ainda mais eficiente de acesso à Justiça, na medida em que o instrumental normativo existente é capaz de afastar os diversos obstáculos tendentes a impedir ou dificultar este acesso.

Atingiu-se, pois, o objetivo inicial da pesquisa de sistematização e análise das normas existentes no NCPC acerca da Defensoria Pública, especialmente se já havia alguma previsão semelhante em normas anteriores, analisando-se as atribuiçôes institucionais e o seu alcance, de forma a permitir a correta compreensão dos instrumentos e funçôes desempenhadas pela Instituição na administração da Justiça.

Em conclusão, pode-se afirmar pelo estudo realizado que, apesar de algumas normas existentes sobre a atuação da Defensoria Pública no NCPC não serem inéditas, é inegável o avanço havido sobre a regulamentação da atuação institucional, destacando-se o efeito da nova codificação processual civil, no mínimo, ratificador do papel de Instituição vocacionada a permitir o efetivo acesso à Justiça das pessoas em situação de vulnerabilidade, seja ela de qualquer ordem (econômica, social, jurídica, organizacional, etc.). 


\section{REFERÊNCIAS}

ALVES, C. F. Justiça para todos! Assistência Jurídica nos Estados Unidos, na França e no Brasil. Rio de Janeiro: Lumen Juris, 2006.

ALVES, C. F.; PIMENTA, M. G. Acesso à Justiça em Preto e Branco: Retratos Institucionais da Defensoria Pública. Rio de Janeiro: Lumen Juris, 2004.

ARAÚjO, J. A. O Litígio Coletivo da Posse dos Artigos 554 e 565 do Novo CPC e a Natureza da Atuação da Defensoria Pública. In: Coleção Repercussóes do Novo CPC. Defensoria Pública, Volume 5, SOUSA, J. A. G. de (coord.), JR. F. D. (coord. geral), Salvador: JusPodivm, 2016.

BUENO, C. S. (coord.). Comentários ao Código de Processo Civil - Volume 1. São Paulo: SaraivaJur, 2017.

CAMBI, E.; OLIVEIRA, P. S. de. Autonomia e Independência Funcional da Defensoria Pública. In: Coleçáo Repercussóes do Novo CPC. Defensoria Pública, Volume 5, SOUSA, J. A. G. de (coord.), JR. F. D. (coord. geral), Salvador: JusPodivm, 2016.

CANTOARIO, D. M. F. Observações sobre a legitimidade da Defensoria Pública no Incidente de Resolução de Demandas Repetitivas. In: Coleçáo Repercussóes do Novo CPC. Defensoria Pública, Volume 5, SOUSA, J. A. G. de (coord.), JR. F. D. (coord. geral), Salvador: JusPodivm, 2016.

CAPPELLETTI, M.; BRAYNT, G. Acesso à Justiça. Trad. Ellen Gracie Northfleet. Porto Alegre: Sergio Antonio Fabris, 1988.

ESTEVES, D.; SILVA, F. R. A. Princípios Institucionais da Defensoria Pública. 2a ed. Rio de Janeiro: Forense, 2017.

FILHO, E. S. G. Defensoria Pública e a Tutela Coletiva de Direitos. Teoria e Prática. Salvador: JusPodivm, 2016.

FLEXA, A.; MACEDO, D.; BASTOS, F. Novo Código de Processo Civil. Temas Inéditos, Mudanças e Supressóes. 2a ed. Salvador: JusPodivm, 2016.

GRINOVER, A. P. Acesso à Justiça e o Código de Defesa do Consumido. In: O Processo em evolução, Rio de Janeiro: Forense Universitária, 1996.

JÚNIOR, A. B. Princípios Institucionais da Defensoria Pública da União. Porto Alegre: Verbo Jurídico, 2014.

JUniOR, N. N.; NERY, R. M. de A. Código de Processo Civil Comentado. 16a ed. São Paulo: Revista dos Tribunais, 2016. 
KIRCHNER, F. Os métodos Autocompositivos na Nova Sistematização Processual Civil e o Papel da Defensoria Pública. In: Coleçáo Repercussóes do Novo CPC. Defensoria Pública, Volume 5, SOUSA, J. A. G. de (coord.), JR. F. D. (coord. geral), Salvador: JusPodivm, 2016.

LIMA, F. R. V. de. Um Novo Código de Processo Civil para Uma Nova Defensoria Pública. In: Coleçáo Repercussóes do Novo CPC. Defensoria Pública, Volume 5, SOUSA, J. A. G. de (coord.), JR. F. D. (coord. geral), Salvador: JusPodivm, 2016.

MAGNO, P. Defensoria Pública e Assistência Jurídica Internacional: Uma Leitura do Novo Código de Processo Civil à Luz do Direito Internacional dos Direitos Humanos. In: Coleçáo Repercussóes do Novo CPC. Defensoria Pública, Volume 5, SOUSA, J. A. G. de (coord.), JR. F. D. (coord. geral), Salvador: JusPodivm, 2016.

MARINONI, L. G.; ARENHART, S. C.; MITIDIERO, D. O Novo Processo Civil. São Paulo: Revista dos Tribunais, 2015.

MENDES, A. G. de C. O Anteprojeto de Código Brasileiro de Processos Coletivos e a Legitimidade da Defensoria Pública para as Açóes Coletivas. In: A Defensoria Pública e os Processos Coletivos. Comemorando a Lei Federal 11.448, de 15 de janeiro de 2007, SOUSA, J. A. G. de (coord.), Rio de Janeiro: Lumen Juris, 2008.

MORAES, G. P. de. Instituiçóes da Defensoria Pública. São Paulo: Malheiros Editores, 1999.

ORDACGY, A. da S. As açóes Coletivas pela Defensoria Pública na novel reforma da Lei Complementar no 80/94. In: Uma Nova Defensoria Pública Pede Passagem. Reflexôes sobre a Lei Complementar 132/09. SOUSA, J. A. G. de (coord.). Rio de Janeiro: Lumen Juris, 2011.

PINHO, H. D. B. de. A Legitimidade da Defensoria Pública para propositura de Açóes Civis Públicas: Primeiras Impressōes e Questôes Controvertidas. In: A Defensoria Pública e os Processos Coletivos. Comemorando a Lei Federal 11.448, de 15 de janeiro de 2007, SOUSA, J. A. G. de (coord.), Rio de Janeiro: Lumen Juris, 2008

RÉ, A. I. Mo. R. O Processo Civil em Xeque: Os Desafios e As Perspectivas de Um Novo Diploma. A Defensoria Pública e seu Papel. In: Coleçáo Repercussóes do Novo CPC. Defensoria Pública, Volume 5, SOUSA, J. A. G. de (coord.), JR., F. D. (coord. geral), Salvador: JusPodivm, 2016.

REIS, G. A. S. dos. O Novo Código de Processo Civil e a Defensoria Pública do Século XXI: O Regime Jurídico de um Novo Ator Processual. In: Coleçáa Repercussóes do Novo CPC. Defensoria Pública, Volume 5, SOUSA, J. A. G. de (coord.), JR. F. D. (coord. geral), Salvador: JusPodivm, 2016.

ROCHA, F. B. Os Impactos do Novo CPC na Defensoria Pública: Intimaçâo Pessoal e Prazo em Dobro Coleção Repercussóes do Novo CPC. Coletiva. In: Coleçâoo Repercus- 
sóes do Novo CPC. Defensoria Pública, Volume 5, SOUSA, J. A. G. de (coord.), JR. F. D. (coord. geral), Salvador: JusPodivm, 2016.

SCHWARTZ, F. O Novo CPC e os Avanços Legislativos que Contribuem na Superação de Obstáculos e na Afirmação da Vocação Institucional da Defensoria Pública para Atuação na Tutela Coletiva. In: Coleçáo Repercussóes do Novo CPC. Defensoria Pública, Volume 5, SOUSA, J. A. G. de (coord.), JR. F. D. (coord. geral), Salvador: JusPodivm, 2016.

SILVA, F. R. A. A Formatação Processual da Defensoria Pública no Novo Código de Processo Civil. In: CPC/2015. Perspectiva da Defensoria Pública, Franklyn Roger Silva (coord.). Salvador: JusPodivm, 2017.

SILVA, H. M. da. Princípios Institucionais da Defensoria Pública. Brasília: Fortium, 2007.

SOUSA, J. A. G. de. A Defensoria Pública e o Código de Processo Civil de 2015: Novos Caminhos - e Responsabilidades - para uma Instituição enfim essencial. In: Coleçáo Repercussóes do Novo CPC. Defensoria Pública, Volume 5, SOUSA, J. A. G. de (coord.), JR. F. D. (coord. geral), Salvador: JusPodivm, 2016. 